\title{
Open disclosure of adverse events: exploring the implications of service and policy structures on practice
}

This article was published in the following Dove Medical Press journal: Risk Management and Healthcare Policy

\author{
Reema Harrison' \\ Merrilyn Walton ${ }^{2}$ \\ Jennifer Smith-Merry ${ }^{3}$ \\ Elizabeth Manias 4,5 \\ Rick ledema ${ }^{6}$ \\ 'Faculty of Medicine, School of Public \\ Health and Community Medicine, \\ UNSW, Sydney, NSW, Australia; \\ ${ }^{2} \mathrm{School}$ of Public Health, Faculty of \\ Medicine and Health, The University \\ of Sydney, Sydney, NSW, Australia; \\ ${ }^{3}$ Centre for Disability Research and \\ Policy, Faculty of Health Sciences, \\ The University of Sydney, Sydney, \\ NSW, Australia; ${ }^{4}$ School of Nursing \\ and Midwifery, Faculty of Health, \\ Centre for Quality and Patient Safety \\ Research, Deakin University, Sydney, \\ NSW, Australia; ${ }^{5}$ Department of \\ Medicine, Royal Melbourne Hospital, \\ Melbourne, VIC, Australia; ${ }^{6}$ Centre for \\ Team-Based Practice and Learning in \\ Health Care, King's College London, \\ London, UK
}

Correspondence: Reema Harrison

Room 308, Samuels Building (F25),

School of Public Health and Community

Medicine, UNSW, Sydney, NSW 2052,

Australia

Tel +6I 293853324

Email reema.harrison@unsw.edu.au
Purpose: The aim of this study was to explore the service and policy structures that impact open disclosure (OD) practices in New South Wales (NSW), Australia.

Participants and methods: An explorative study using semi-structured interviews was undertaken with 12 individuals closely involved in the implementation of OD in hospitals at policy or practice levels within the state of NSW, Australia. Interviews explored the service and policy structures surrounding OD and the perceived impact of these on the implementation of the OD policy. These data were thematically analyzed to understand the factors facilitating and creating barriers to openness after adverse events.

Results: The data identified three key areas in which greater alignment between OD policy and the wider service and policy structures may enhance the implementation of OD practice: 1) alignment between OD and root cause analysis processes, 2) holistic training that links to other relevant processes such as communicating bad news, risk management, and professional regulation and insurance, and 3) policy clarification regarding the disclosure of incidents that result in no or low-level harm.

Conclusion: Evidence from this study indicates that formal OD processes are not routinely applied after adverse events in NSW, despite clear guidelines for OD. The reasons for this are unclear as the service-level and policy-level phenomena that support or hinder OD are understudied. This knowledge is critical to addressing the policy-practice gap. Our paper provides insights regarding the influence of current service-level and policy-level phenomena on the delivery of OD and how policy clarification may contribute to addressing some of the challenges for implementing OD policy. The principles of virtue ethics - specifically, openness and the involvement of service users - may contribute to progressing in this area.

Keywords: incident disclosure, adverse events, health policy, hospitals, patient-centered care, qualitative research

\section{Introduction}

Open disclosure (OD) is "an open discussion with a patient about an incident(s) that resulted in harm to that patient while they were receiving health care". ${ }^{1}$ The principles underpinning OD were established over 25 years ago in the USA and remain constant; health care providers should openly and honestly discuss incidents that occur during health care that cause harm to patients. ${ }^{2,3}$ The first OD policy was implemented by the Department of Veterans Affairs in the USA in 1995, while the Australian National Disclosure Standard was created by a multidisciplinary committee established by Standards Australia in 2003. Other English speaking countries gradually implemented 
OD approaches over the next decade, although sometimes using a different approach or terminology such as Being Open (and the related arguments for a "duty of candor") or "honest disclosure" (in the UK) and "full disclosure" (in the USA).

Policy makers, clinicians, and patients agree that transparency and honesty after adverse events are beneficial for patient care; yet, the implementation of OD in practice has been challenging. ${ }^{2}$ Evidence to date highlights the uncertainties and interpersonal challenges associated with OD practice in studies with patients and health professionals. ${ }^{4-7}$ While the ethical arguments for OD are strong, there are many stakeholders, and the implementation of OD is impacted by their perspectives. Barriers to OD have been identified for different stakeholders internationally; specifically, health professionals' fears of litigation or damaged reputation. ${ }^{4}$ While several studies have explored health professional and patient perspectives of OD and the role of apology laws in this context, less is known about the influence of servicelevel phenomena and policy governance phenomena, such as existing service strategies, and local policies and procedures (both formal and informal) used by services to communicate about adverse events. ${ }^{8}$

\section{Policy and practice context}

All states and territories in Australia have an OD policy. ${ }^{9}$ OD was mandated in 2003 by the Australian Commission on Safety and Quality in Health Care when it published the National Safety and Quality Health Services Standards (the National Standards). Standard 1 "Governance for Safety and Quality in Health Care Organisations" of the 2012 National Standards included appropriate OD structures and staff training, essential to enable "patient safety and quality incidents [to be] recognized, reported and analysed, and this information... used to improve safety systems". ${ }^{1}$ This is reflected in the second edition of the Standards. ${ }^{10}$

Additionally, the Australian Open Disclosure Framework was developed to guide OD practice in Australian health care. ${ }^{11}$ This framework positions OD as an ethical obligation when providing care, has been endorsed by major practitioner bodies regulating practice for nurses, pharmacists, doctors, pathologists, and emergency medicine workers, and defines the elements of OD. ${ }^{11}$

The New South Wales (NSW) Health Open Disclosure Policy provides mandatory guidelines for OD in NSW health facilities. $^{12}$ The guidelines in this state are comparable to those situated in other Australian jurisdictions such as West and South Australia. 13,14 The NSW Policy requires "health services boards, clinical councils, and staff" to conduct and record OD, and chief executives to oversee policy implementation, making OD a generic responsibility of those in the NSW health system. The process is outlined in Box 1.

\section{Challenges for practice}

Despite the detailed guidance and support relating to the practice of OD across Australia, recent large-scale data collected from patients in NSW showed that formal OD processes only took place in $17 \%$ of instances in which a patient had an adverse event. ${ }^{15}$ This is despite the state-wide OD training that NSW Health implemented in high-level ODs over a decade ago. ${ }^{16}$ Current evidence indicates that a number of service structure, policy, and administrative factors, in the context of OD, may be barriers to adopting OD processes consistent with organizational, state, or national policies. ${ }^{9}$ The 2008 evaluation of the national implementation (with data collected from hospitals in Queensland, South Australia, Tasmania, NSW, and Victoria) of the national OD policy noted a number of features of the health care system and process impacted on the implementation of OD. ${ }^{17}$ These features included the interplay between incident investigation processes and OD and professional roles, role boundaries, work routines, and communication skills. ${ }^{17}$ The latter has been the focus of interventional approaches aiming to enhance OD practice. ${ }^{18}$

While evidence from systematic reviews of OD suggests that the current policy guidance may not sufficiently address the issues arising in OD practice due to the structure and processes of health care delivery, data from policy makers

Box I Mandated process for conducting open disclosure in New South Wales health facilities

- Acknowledgement of a patient safety incident to the patient and/ or their support person(s), as soon as possible, generally within 24 hours of the incident...

- Truthful, clear, and timely communication on an ongoing basis as required.

- Providing an apology to the patient and/or their support person(s) as early as possible, including the words "I am sorry" or "we are sorry".

- Providing care and support to patients and/or their support person(s) which is responsive to their needs and expectations, for as long as is required.

- Providing support to those providing health care which is responsive to their needs and expectations.

- An integrated approach to improving patient safety, in which open disclosure is linked with clinical and corporate governance, incident reporting, risk management, complaints management, and quality improvement policies and processes...

- Multidisciplinary involvement...

- Compliance with legal requirements for privacy and confidentiality...

Notes: Data from Finlay et al. ${ }^{9}$ 
and health service managers regarding the barriers to OD from the policy and service delivery levels are lacking. ${ }^{5,6,19}$ To address this gap, individual interviews were undertaken with key informants involved in policy development and health service delivery in the state of NSW, Australia. The interviews were designed to explore the depth of knowledge of the OD policy, their experience of the policy and current practice, and the service structure and policy barriers perceived as impeding effective policy implementation in NSW.

\section{Participants and methods}

Semi-structured interviews with health service managers and policy makers who had responsibility for and an interest in OD were undertaken between June and December 2015 as part of a larger study of patients' experiences of adverse events and OD in NSW hospitals. The results of the patients' experiences of adverse events study are discussed elsewhere (references removed for blinding). The data in this paper contextualize the policy by providing an understanding of the broader clinical, administrative, and policy context surrounding adverse events. Given consistent evidence of the diverse meanings given to the term "open disclosure" and the variation in practice, interviewees were first asked about their experience and understanding of OD and that of their colleagues. In the second part of the interview, they were asked about their perceptions of the service and policy influences, such as existing service strategies, and local policies and procedures (both formal and informal) used by services to communicate about adverse events on practice.

\section{Ethics and research governance approval}

The study received ethics approval from the NSW Population and Health Services Research Ethics Committee. Research governance approval was also given for interviews conducted in NSW Health sites.

\section{Sample}

Key informants were sought who had particular knowledge and understanding of the operationalization of $\mathrm{OD}$ at a range of

Box 2 Definition of the national open disclosure policy

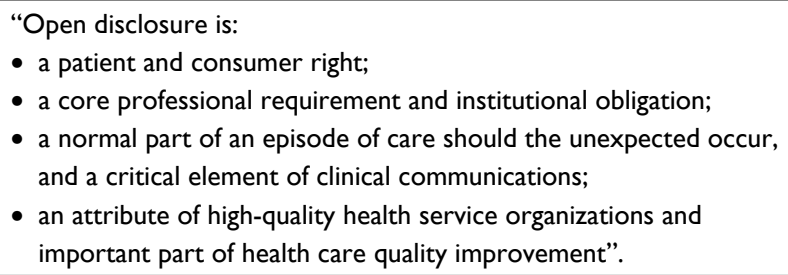

Notes: Data from McDonnell and Guenther. ${ }^{8}$ levels in the health sector, from the clinical frontline to medical defense. Key informants provided insights on the nature of the challenges in implementing OD in terms of the structure and process of health care, and to provide recommendations relating to these challenges. A purposive sample of health service managers involved in policy development and service delivery from local health districts covering urban, regional, and remote areas, the health department, and medical defense organizations were invited to participate as key informants. Potential participants were identified by the project reference group involving researchers, policy makers, and clinicians with an expertise in adverse event management. They identified the health manager positions and roles which would be engaged in OD in hospitals across NSW (as detailed in Table 1), and were then invited to take part via direct email from the research team to avoid coercion. Key informants were purposively sampled to ensure that perspectives were captured from a range of organizations and roles relating to the implementation of OD. All participants were at a senior level and had been in their current roles for $>12$ months. Study information sheets and a consent form were included in the invitation email. Table 1 shows the basic role descriptions of interview respondents.

A total of 12 interviews were conducted between June and December 2015. Eight respondents were interviewed who had direct responsibilities for addressing adverse events as clinician managers or as health service managers supporting clinicians during the OD process. The remaining four respondents worked in government policy roles or in medical defense organizations, which supported health professionals involved in adverse events.

\section{Interview schedule}

Semi-structured interviews provide an in-depth understanding of respondent experiences with the capacity to follow-up

Table I Responder roles and organization (C: hospital based; P: policy or legal organization)

\begin{tabular}{|l|l|}
\hline Respondent role/organization & Identifier \\
\hline Nurse manager & $\mathrm{Cl}$ \\
Medical defense & $\mathrm{PI}$ \\
Medical defense & $\mathrm{P} 2$ \\
Clinical governance officer & $\mathrm{C} 2$ \\
Patient safety officer & $\mathrm{C} 3$ \\
Clinical governance director & $\mathrm{C} 4$ \\
Government legal advisor & $\mathrm{P} 3$ \\
Government policy advisor & $\mathrm{P} 4$ \\
Patient safety officer & $\mathrm{C} 5$ \\
Director of nursing & $\mathrm{C} 6$ \\
Clinical governance director & $\mathrm{C} 7$ \\
Clinical governance director & $\mathrm{C} 8$ \\
\hline
\end{tabular}


interesting lines of enquiry and to clarify unclear responses. An interview schedule focusing on practices and policy context relating to adverse events including OD was developed. The research advisory committee reviewed the questions for content validity. Questions differed slightly between respondents involved in clinical care and those working at a policy or administrative level. Irrelevant questions relating to either clinical care or policy were removed as needed. All respondents in this study were working in NSW Health and were asked specifically about OD experiences and the operationalization of OD in this context.

Initial questions to the respondents covered their role and responsibilities for adverse events. Respondents in clinical settings provided an example of an adverse event and described how it was managed, who was involved, and what information was collected. Respondents from policy and legal settings spoke about their knowledge of adverse events, observation of its practice, and data collection and policy associated with adverse events. Additional questions focused on organizational roles associated with adverse events and the collection and use of data captured about patient experiences of adverse events. Prompts were used to gather further information relating to these questions as needed. Respondents spoke from their own perspective and referred to both their own experiences and their observations of others.

\section{Procedure}

All interviews were conducted by two authors (RH, JSM) over the phone and audio recorded. After obtaining consent, the interview schedule was used to guide discussion with participants, who were also given the opportunity to shape the discussion and develop their own narratives. Interviews lasted 30-45 minutes each. Identifiable features of participants were removed by anonymizing audiotapes and direct quotations. Audio recordings were securely stored and transcribed for analysis.

\section{Analysis}

Transcripts were analyzed thematically using an established interpretive approach. ${ }^{20}$ Following initial basic thematic coding for themes and content, the authors extracted data relating to OD from the main data set. These data were then further analyzed for themes relating to the following questions:

- What does the respondent understand by the term OD?

- To what extent does the respondent believe that current OD practices reflect the NSW Health OD policy?

- What were the respondent perceptions of structural or service-related impediments to OD policy implementation?
NVivo 8 text management software (QSR International, Melbourne, VIC, Australia) was used to mark specific pieces of interview data that were identified as corresponding to the thematic index codes. More generally, NVivo 8 was also used to help organize the data to facilitate further analytic consideration and interpretation. Data were categorized according to research questions and discussions formed around the main themes that arose from the data.

\section{Results}

\section{Knowledge of OD}

While most respondents were aware of OD policies, the results identified varied understandings about OD and, despite their roles and responsibilities, few could explain the institutions and/or government policies on OD. Respondents demonstrating a higher level of understanding of the operationalization of OD policies and processes worked in medical defense organizations. Respondents identified clinicians treating patients as having least understanding of the policy.

Respondents reported that staff working on the clinical front line had a basic understanding of OD but lacked in-depth knowledge about conducting an OD process or of the policy context. One respondent's comment of staff was "They're all aware of OD. They may not be aware of the policy, or the content, but they're certainly aware..." of the necessity of OD (C4). They also said that staff, even if aware of the policy, had little "understanding how to use it..." (C4). Respondents stated that OD education was offered to staff in hospitals (C6, C8, C4) and medical defense organizations offered training to their members (P1). However, training was not universally accessed (C8), and another commented that it was sporadic (C2).

\section{$O D$ in practice}

Only two respondents gave examples consistent with accepted OD practices (C4, C7). Respondent accounts described implementation of OD being incorrectly done and not in accordance with specific processes mandated within the NSW OD policy (articulated in Box 2) (C4, C6, C8). Two consistent deviations from the OD policy were noted. First, the person/s leading the OD was often the most senior staff member rather than the health professionals involved as part of a multidisciplinary team (C8). In other accounts (C4), it was the nurse or administrative staff at arm's length to the adverse event rather than clinicians who had been directly involved in the event who conducted OD.

Second, the timing of OD lacked clarity in relation to when a root cause analysis (RCA) was to occur. The undertaking of an RCA was often discussed as running alongside an 
OD, such that the timing and content of OD were informed by the stage of and knowledge produced through an RCA process. Although an RCA aims to ascertain the multiple underlying factors that contribute to an adverse event it was conceptualized as a separate process, but one that was seen to inform the OD process. A second OD process following RCA was noted by multiple respondents (C3, C5, C2). One respondent said an "informal" OD would occur within 24 hours of an event, but the "formal OD" would only occur after the completion of an RCA (C3). The respondents indicated that a "formal OD" $(\mathrm{C} 2, \mathrm{C} 3, \mathrm{C} 5)$ often referred to a postRCA meeting between staff and patients/family members. A third final area in which views regarding OD appeared inconsistent was in the disclosure of less serious events, defined by the degree and duration of patient harm associated with an event. The current policy defines higher and lower level response pathways, which reflect the different OD processes that respondents reported using for serious and less serious events (C8). The approach to low-level disclosures was poorly defined and appeared subject to substantial variation. For example, one respondent identified the use of the formal approach for events that were lower level (C6) where another described a more informal bedside discussion, reflecting the difficulty of deciding on the severity of an incident (C8).

\section{Impediments to OD}

These uncertainties about how to realize OD also impacted on how interviewees felt about identifying OD team members and identifying an appropriate time for OD. One respondent commented that applying OD in line with the policy is more difficult when harm was not immediately recognized. A respondent described the difficulty of getting the team together for an OD after a patient had been discharged and several days later committed suicide. Further challenges included the reluctance of some clinicians to be involved as they did not accept the suicide was caused by their actions as the act was "seemingly" separate from their health care (C7).

The types of events disclosed and the timing of OD were discussed in the context of inadequate or unsuitable training with several respondents saying OD was a "difficult" process ( $\mathrm{P} 2, \mathrm{P} 4, \mathrm{C} 6)$ noting that practitioners were not trained in or comfortable with disclosing. Some practitioners were seen to be naturally just "better than others" at undertaking OD discussions (P1). Respondents discussed how practitioners would benefit from training in communication skills, including how to have "difficult conversations" (P1, C6). Written OD guidelines were viewed as a poor substitute for well-developed interpersonal skills (C6). One medical defense organization respondent described the need for a "fact sheet" for doctors explaining "how to say sorry" (P1). Another mentioned the need for staff to be taught how to apologize properly (C6).

Lack of alignment between training and the requirements of OD and concern about legal ramifications of adverse event disclosure constrained the implementation of OD. Myths about the legal ramifications of apology were highlighted (P1, P4, C5). The medical defense organization respondents reported that doctors regularly contacted them in order to receive legal advice about the $\mathrm{OD}$ process $(\mathrm{P} 2, \mathrm{P} 1)$ : "Some of them are worried about compromising their insurance position - almost seeking permission from us to say sorry or apologize, because they worry if they go in and say too much then that might cause a problem with their insurance" (P1).

Views about inadequate policy implementation and available support for health professionals involved in adverse events also had an impact on the quality of OD. Respondents reported that clinicians were being exposed to negative professional and personal outcomes through OD, and needed extra support to enable them to conduct OD (P1, C2, C4). One facility employed "OD coordinators" who joined in on OD meetings to ensure OD compliance with local OD policy and support clinicians (C3).

Patients' lack of knowledge about the existence of, or the need for, OD was a final impediment. One respondent stated that a request to conduct OD was frequently not accepted by patients (in up to $50 \%$ of cases), often because they did not perceive the process to be helpful and/or necessary (C8).

\section{Discussion}

Despite substantial evidence of inadequate or absent OD processes in relation to adverse events in health care, knowledge of the hospital structures and policy influences contributing to the disclosure of adverse events is limited. ${ }^{16}$ Our data identified three key areas in which greater alignment between OD policy and the wider service and policy structures in NSW health services may enhance the implementation of OD practice: 1) alignment between OD and RCA processes, 2) holistic training that links to other relevant processes such as communicating bad news, risk management, and professional regulation and insurance, and 3) policy clarification regarding incidents that result in no or low-level harm. Each of these was identified over 10 years ago in the evaluation of the national OD implementation as challenges. ${ }^{14}$ Our study and international data show that these challenges have turned into reality.

The current NSW OD policy requires that OD should always occur in the context of adverse events, events in which patients are harmed physically or psychologically. Therefore, 
OD should always feature if there is an incident investigation or an RCA. Guidelines across Australia acknowledge the interrelationship between RCA and OD processes which can both contribute to analyzing causes of harm and taking steps to strengthen the system. ${ }^{20}$ Less clear is the optimal approach for undertaking OD in the context of an incident investigation. Our data suggest that this lack of clarity concerning the interplay between the two processes may lead to delayed OD while the facts of the incident are investigated. Policy clarification specifying the requirement for a preliminary OD discussion and the nature of its content may be of value. This issue was identified in the evaluation of the national OD implementation in Australia as requiring greater integration between RCA and OD, with OD informing RCA investigation processes as the minimum requirement. Some progress has been made toward this integration; for example, in Queensland, affected service users are involved in RCA investigations and there are similar examples in the USA. ${ }^{21}$

Policy clarification is also required regarding incidents that result in no or low-level harm. Data collected from the present sample reflect growing evidence from health professionals internationally highlighting confusion regarding the need for and nature of OD in instances of no or low-level harm. ${ }^{4}$ Determining the severity of an event and related need for disclosure has been discussed in the US context. A number of approaches have been identified to assist health professionals to manage the uncertainties around when disclosure is required. Approaches to guide judgements regarding the need for disclosure include the need to establish whether patients/ families expect an explanation for aspects of care that they have questions about; exploring whether aspects of care that clinicians have questions about are ones that patients/families have questions about; and being prepared to be open about these questions and their possible answers with patients/families who want to know. ${ }^{22}$ The Australian national policy guidance outlines a higher or lower level response determined by factors such as degree of patient harm and the duration of this but provides little guidance regarding the approach taken in lower level events. ${ }^{11}$ As such, our data identified diverse views regarding when to share information with patients and what information should be shared. Given that health professionals cite fears of litigation, reputational loss, loss of patient trust in the system, and blame as reasons for not practicing OD for non-harmful events, work is needed to promote principles of openness and honesty throughout health care through a culture in which health professionals experience psychological safety. ${ }^{4}$

In our data and elsewhere, OD appears to be conceptualized as a process relating to quality within the incident management process rather than as part of a wider movement toward patientcentered care, with a distinct training package and program of work. $^{23,24}$ Patient-centered communication and professionalism training that links to training about communicating bad news, risk management, professional regulation, and insurance may assist health professionals to determine for themselves what to disclose, when to bring this into the conversation, and how to do so appropriately. In 2008, Iedema et al described OD as "a dynamic and complex process that cannot be fully proceduralised, staff need to apply professional, organizational and ethical judgments when determining which events to disclose" ${ }^{17}$ Our findings suggest that this aspect of OD remains the key challenge, one which may be best addressed by both policy clarification and better integration of OD within other professional skills development.

While the mantra "do no harm" and the ethical obligation to be honest with patients are embedded in medical ethics, they alone have not been sufficiently robust to ensure patients are informed of adverse events. The complexity of health care today inherently changes the nature of the doctor-patient relationship with the consequence that it is not always easy to put patient interests first, even for clinicians with the best of intentions. ${ }^{23}$ More is required than dependence on the moral responsibilities of individual clinicians. OD principles do not replace these ethical tenets. Rather, they provide a framework to guide health professionals through a process that respects a patient's right to know. Policies describing disclosure of adverse events have roots in patient safety, not ethical theories or philosophy. Patient safety is not just about an outcome of care; it also entails a set of patient-centered competencies designed to minimize harm and improve quality of care.

The study is likely to be useful for international audiences to consider when exploring the challenges of implementing local incident disclosure policies. While local, state, and national policies vary, OD policies internationally operate on the same fundamental principles. A central issue for many operationalizing these policies is how disclosure policies interplay with RCA processes when being undertaken in the context of an RCA. In contrast to RCA processes, training and development regarding OD skill and knowledge is not positioned as a distinct program and this varies from one context to another. For example, in Brigham and Women's Hospital in the USA, OD education and training is positioned with the Center for Professionalism and Peer Support. ${ }^{24}$ Further work to explore the implications of this integration with other professional skills would be valuable to understand the implications for OD practice.

This study is limited by its geographical restriction to only NSW, Australia. However, in NSW all states and territories 
in Australia operate under the same national standards. Key informant interviews were used to provide a range of perspectives from those who would have in-depth understanding and experience of the operationalization of OD throughout the health sector. The approach reflects that of similar studies in the health care sector that explore a particular policy or issue. ${ }^{25}$ We did not seek to achieve information saturation here because we were exploring common challenges and obstacles in the operationalization of OD, which may occur in many forms and do not align with the concept of saturation. It is, however, possible that undertaking further interviews would offer new perspectives not presented by the key informants here.

\section{Conclusion}

Evidence from this study indicates that formal OD processes are not routinely applied after adverse events in NSW, despite clear guidelines for OD. The reasons for this are unclear as the service and structure that support or hinder OD are understudied. This knowledge is critical to addressing the policy-practice gap. Our paper provides insights regarding the influence of current service and policy structures on the delivery of OD and how policy clarification may contribute to addressing some of the challenges for implementing OD policy. Key areas for policy clarification relate to the interplay between the OD and related approaches such as RCA of safety events and the provision of patient-centered care.

\section{Disclosure}

The authors report no conflicts of interest in this work.

\section{References}

1. Australian Commission on Safety and Quality in Health Care (ACSQHC). National Safety and Quality Health Services Standards, 2012. Sydney: ACSQHC; 2012. Available from: https://www.safetyandquality.gov.au/wp-content/uploads/2011/09/NSQHS-StandardsSept-2012.pdf. Accessed July 16, 2018.

2. Walton M. Do The Right Thing. A New Way to Manage Mistakes. Australian and New Zealand College of Anaesthetists; 2003:41-49.

3. Allan A, Munro B. Open Disclosure: A Review of the Literature. Joondalup: Edith Cowan University; 2008. Available from: https://www. ecu.edu.au/_data/assets/pdf_file/0005/685274/86_Allan_OD_Literature_Review.pdf. Accessed October 22, 2018.

4. Birks Y, Entwistle V, Harrison R, Bosanquet K, Watt I, Iedema R. Being open about unanticipated problems in health care: the challenges of uncertainties. J Health Serv Res Policy. 2015;20(1 Suppl):54-60.

5. Iedema R, Sorensen R, Manias E, et al. Patients' and family members' experiences of open disclosure following adverse events. Int J Qual Health Care. 2008;20(6):421-432.

6. Harrison R, Birks Y, Bosanquet K, Iedema R. Enacting open disclosure in the UK National Health Service: a qualitative exploration. $J$ Eval Clin Pract. 2017;23(4):713-718.

7. Walton M, Harrison R, Smith-Merry J, et al. Disclosure of adverse events: a data linkage study reporting patient experiences among Australian adults aged $\geq 45$ years. Aust Health Rev. Epub 2018 Apr 26.

8. McDonnell WM, Guenther E. Narrative review: do state laws make it easier to say "I'm sorry?" Ann Intern Med. 2008;149(11):811-815.
9. Finlay A, Stewart C, Parker M. Open disclosure: ethical, professional and legal obligations and the way forward for regulation. Med J Aust. 2013;198(8):445-448.

10. Australian Commission on Safety and Quality in Health Care (ACSQHC). National Safety and Quality Health Services Standards. 2nd ed. Sydney: Australian Commission on Safety and Quality in Health Care; 2017. Available from: https://www.safetyandquality.gov.au/ our-work/assessment-to-the-nsqhs-standards/nsqhs-standards-secondedition/. Accessed July 16, 2018.

11. Australian Commission on Safety and Quality in Health Care (ACSQHC). Australian Open Disclosure Framework. Sydney: ACSQHC; 2013. Available from: https://www.safetyandquality.gov.au/ wp-content/uploads/2013/03/Australian-Open-Disclosure-FrameworkFeb-2014.pdf. Accessed July 16, 2018.

12. New South Wales Health. Open disclosure policy; 2014. Available from: https://www1.health.nsw.gov.au/pds/ActivePDSDocuments/ PD2014_028.pdf Accessed July 16, 2018.

13. Government of Western Australia, Department of Health. Open disclosure policy statement; 2015. Available from: https://ww2.health. wa.gov.au/About-us/Policy-frameworks/Clinical-Governance-Safetyand-Quality/Mandatory-requirements/WA-Open-Disclosure-Policy. Accessed July 16, 2018.

14. Government of South Australia, SA Health. Patient incident management and open disclosure: policy directive; 2016. Available from: http://www. sahealth.sa.gov.au/wps/wcm/connect/89e269804e341 fb5b45ffcc0934 $3 \mathrm{dd} 7 \mathrm{f} /$ corrected+Patient+Incident+management+and+OD_final+29-9$17+$.pdf?MOD=AJPERES\&CACHEID=ROOTWORKSPACE89e269804e341fb5b45ffcc09343dd7f-1XKGZe-. Accessed July 16, 2018.

15. Walton MM, Harrison R, Kelly P, et al. Patients' reports of adverse events: a data linkage study of Australian adults aged 45 years and over. BMJ Qual Saf. 2017;26(9):743-750.

16. Iedema R, Jorm C, Wakefield J, Ryan C, Dunn S. Practising open disclosure: clinical incident communication and systems improvement. Sociol Health Illn. 2009;31(2):262-277.

17. Iedema R, Mallock N, Sorensen R, et al. Final Report: Evaluation of the Pilot of the National Open Disclosure Standard. Sydney: University of Technology, Sydney; 2008. Available from: https://www.safetyandquality.gov.au/wp-content/uploads/2012/04/Evaluation-of-Pilot-ofthe-National-Open-Disclosure-Standard-Final-Report-Nov-2007.pdf. Accessed January 15, 2019.

18. Gallagher TH, Denham CR, Leape LL, Amori G, Levinson W. Disclosing unanticipated outcomes to patients: the art and practice. $J$ Patient Saf. 2007;3(3):158-165.

19. Birks Y, Harrison R, Bosanquet K, et al. An exploration of the implementation of open disclosure of adverse events in the UK: a scoping review and qualitative exploration. Health Serv Deliv Res. 2014;2(20):1-196.

20. Braun V, Clarke V, Terry G. Thematic analysis. Qual Res Clin Health Psychol. 2014;24:95-114.

21. McDonald TB, Helmchen LA, Smith KM, et al. Responding to patient safety incidents: the "seven pillars". BMJ Qual Saf. 2010;19(6):e11.

22. Wu A, Gallagher TH, Iedema R. Disclosing close calls to patients and their families. In: Wu A, editor. The Value of Close Calls. Oakbrook Terrace, IL: Joint Commission US; 2010.

23. Walton M, Kerridge I. Do no harm: is it time to rethink the Hippocratic Oath? Med Educ. 2014;48(1):17-27.

24. Brigham and Women's Hospital. Center for professionalism and peer support. Available from: https://www.brighamandwomens.org/medicalprofessionals/center-for-professionalism-and-peer-support/disclosureand-apology. Accessed October 22, 2018.

25. Mannion R, Blenkinsopp J, Powell M, et al. Key informant interviews. Understanding the knowledge gaps in whistleblowing and speaking up in health care: narrative reviews of the research literature and formal inquiries, a legal analysis and stakeholder interviews. Health Services and Delivery Research. Southampton, UK: NIHR Journals Library; 2018. 
Risk Management and Healthcare Policy is an international, peer-reviewed, open access journal focusing on all aspects of public health, policy, and preventative measures to promote good health and improve morbidity and mortality in the population. The journal welcomes submitted papers covering original research, basic science, clinical and epidemiological studies, reviews and evaluations, guidelines, expert opinion and commentary, case reports and extended reports. The manuscript management system is completely online and includes a very quick and fair peerreview system, which is all easy to use. Visit http://www.dovepress.com/ testimonials.php to read real quotes from published authors.

Submit your manuscript here: https://www.dovepress.com/risk-management-and-healthcare-policy-journal 